Article

\title{
Optimisation Techniques for Managing the Project Sustainability Objective: Application to a Shell and Tube Heat Exchanger
}

\author{
Juan José Cartelle Barros ${ }^{1, *(D)}$, Manuel Lara Coira ${ }^{2}$, , María Pilar de la Cruz López ${ }^{3}$ (D), \\ Alfredo del Caño Gochi ${ }^{3}\left(\mathbb{D}\right.$ and Isabel Soares ${ }^{4}(\mathbb{C}$ \\ 1 Escuela Politécnica Superior (EPS), Universidade da Coruña (UDC), Campus de Esteiro, C/Mendizábal s/n, \\ 15403 Ferrol (A Coruña), Spain \\ 2 Departamento de Ciencias de la Navegación e Ingeniería Marina, Escuela Politécnica Superior (EPS), \\ Universidade da Coruña (UDC), Campus de Esteiro, C/Mendizábal s/n, 15403 Ferrol (A Coruña), Spain; \\ mlara@udc.es \\ 3 Departamento de Ingeniería Civil, Escuela Politécnica Superior (EPS), Universidade da Coruña (UDC), \\ Campus de Esteiro, C/Mendizábal s/n, 15403 Ferrol (A Coruña), Spain; pcruz@udc.es (M.P.d.l.C.L.); \\ alfredo@udc.es (A.d.C.G.) \\ 4 Research Centre on Economics and Finance (CEFUP) and Faculty of Economics, University of Porto, \\ Rua Dr Roberto Frias S/n, 4200-464 Porto, Portugal; isoares@fep.up.pt \\ * Correspondence: juan.cartelle1@udc.es
}

Received: 5 April 2020; Accepted: 28 May 2020; Published: 1 June 2020

\begin{abstract}
In addition to traditional project management objectives (cost, time, scope and quality, among others), it is now necessary to include a global sustainability objective in all projects, regardless of their nature and scale. The processes for managing this objective may include sub-processes for optimising the sustainability of some or all of the project's deliverables. In this paper an integrated optimisation technique was applied to optimise the design of a shell and tube heat exchanger (STHE) by taking into account economic, social and environmental indicators. A case study previously analysed in the literature, although with different objectives and scope, was considered for such a purpose. Diverse sets of weights were defined for the environmental impacts, as well as two additional cases. In the first one, all the indicators where assessed in a linear way. Non-linearities were studied in the second one. Both non-nature-inspired (exhaustive search and Monte Carlo simulation) and nature-inspired (Particle Swarm Optimisation, Crow Search Algorithm and Non-dominated Sorting Genetic Algorithm-II) optimisation techniques were used to solve the problem. The results were presented and discussed in depth. The findings show the necessity of applying these kinds of methodologies in the design of energy systems and, in particular, STHEs.
\end{abstract}

Keywords: project management; global sustainability objective; engineering problem; sustainability optimisation; shell and tube heat exchanger; optimisation techniques; nature-inspired algorithms

\section{Introduction}

\subsection{Framework and General Background}

A project can be defined as a set of coordinated activities carried out during a limited time period with the objective of creating a product, service or other outcome. Typically, project managers have to deal with objectives in terms of scope, cost, time and quality. However, it is nowadays necessary to go further by including an integral sustainability objective in all projects, regardless of their nature and scale. The processes for managing this objective may include sub-processes for optimising the 
sustainability of some or all of the project's deliverables, under the guidance of the project manager. A framework for managing the project's sustainability objective may include processes for (1) planning; (2) establishing the Sustainability Breakdown Structure, when different sustainability assessment models are to be applied to the various subsystems of the project; (3) defining the sustainability objective, with the potential establishment of partial environmental, social and economic objectives; (4) identifying project alternatives, such as the use of different designs, or the utilization of products from different manufacturers; (5) defining the sustainability strategy, by assessing the sustainability of the alternatives generated in the previous process, and choosing those that allow the sustainability objective to be achieved; and (6) monitoring and control.

In a framework like this, during the planning process (Process 1), the project team will have to decide whether or not to use optimisation techniques for any deliverable, as well as which techniques to apply. On the other hand, these techniques will be applied during the process of defining the sustainability strategy (Process 5), as will be seen in this article. Finally, during the monitoring and control process (Process 6) and, more specifically, when re-assessing sustainability and estimating the potential final sustainability level, it may be necessary to perform new optimisation calculations. This will allow for timely decision-making to modify the project's sustainability strategy, when necessary.

At the time of designing an engineering system, it is crucial to adopt an economic perspective [1]. In fact, from a technical perspective, the best solution will not be valid if economic results are not satisfactory. Therefore, a considerable number of studies were published addressing engineering problems by taking into account economic factors [2], namely those which concern the energy sector. By way of example, Moore et al. [3] analysed how the condenser design of a concentrated solar power plant can affect its performance by conducting a techno-economic analysis.

Moreover, as environmental impact remains a major concern [4,5], it is necessary to go further. Therefore, it makes sense to analyse not only the nexus between economic and technical issues, but also the role that the potential environmental effects can play [6]. There are some studies in which the authors consider environmental issues in the design of engineering and energy systems. By way of example, Shirazi et al. [4] optimised an ice thermal energy storage system including thermodynamic, environmental and economic objective functions.

On the other hand, it has been many years since the concepts of sustainable development and integral sustainability have been coined in the Brundtland report [7] and in the Rio Declaration [8]. Both concepts go beyond environmental issues, since every human shall enjoy a productive and healthy life. Consequently, social factors also appear as significant aspects of sustainability. In other words, environmental, economic and technical indicators are necessary but not sufficient to achieve sustainable development. This is the main reason why it is necessary to look beyond these issues at the time of designing engineering systems, by developing studies in which the integral or global sustainability (economic, social and environmental dimensions) is considered.

In this line, there are some cases in which the authors assessed the sustainability of energy systems. For example, Manara and Zabaniotou [9] focused on a small gasification bioenergy system.

On the basis of the above, it is clear that, at the time of designing engineering systems, more and more engineers and researchers take into account social and environmental issues apart from the economic and technical ones. This is no doubt a positive trend towards sustainable development. Nevertheless, assessing global sustainability is not enough. The aim should be to optimise the sustainability of engineering systems, in the sense of maximising their contribution to sustainable development. In other words, in the same way that it is common to adopt economic (cost minimisation) and technical (performance maximisation) objectives, it is now necessary to establish a sustainability goal to be maximised, by taking into account economic, social and environmental sub-objectives. We are therefore facing a complex optimisation problem, since there can be conflicts between the indicators.

The sustainability optimisation of energy systems is still in its infancy, although there are some examples (i.e., Y1lmaz Balaman et al. [10]). However, there is some scope for improving by, for example, 
analysing all the sustainability pillars (economic, social and environmental) in depth or defining an integrated framework valid for different systems and scales, among others. The ideal is to start with an energy system with a limited number of design variables. This would facilitate the solution of the optimisation problem. At the same time, it is desirable that the selected system presents an extensive number of applications in different industries [11-14]. In this context, the design of a shell and tube heat exchanger (STHE) provides a good starting point. It is important to note that if the STHE is industrially mass-produced for a specific application, the importance of optimising its sustainability increases significantly. Furthermore, the model and the methodology employed in the sustainability optimisation of a specific STHE can be used to optimise other STHEs, even other similar energy systems, after introducing the corresponding modifications. The reader can find in Section 1.2 a brief literature review addressing the optimisation of STHEs.

\subsection{Literature Review}

The optimisation of STHEs is not new. For example, Patel and Rao [11] studied the economic optimisation of STHEs by using the Particle Swarm Optimisation (PSO) technique. Hadidi et al. [12] pursued the same objective but, this time, using the Imperialist Competitive Algorithm (ICA). Similar studies, with different optimisation techniques, are the ones performed by Mariani et al. [13] (chaotic quantum PSO), and Dhavle et al. [14] (Cohort Intelligence Algorithm (CIA)), among others.

There are other studies in which a multi-objective optimisation is performed by taking into account the costs together with the thermal effectiveness $[15,16]$. Notwithstanding, other aspects that fall within the scope of the integral sustainability are rarely studied, such as the different environmental impacts or the employment generation. As far as the authors know, there is only one paper addressing the sustainability optimisation of a STHE [17]. Despite its novel aspects, [17] presents some limitations. For example, only five environmental impacts were taken into account. It is important to remark that there is a considerable number of environmental impacts that are quite often ignored in the scientific literature. Therefore, the aim of this work is to cover this gap and also to study in greater depth the sustainability optimisation in engineering problems.

\subsection{Objectives and Novel Contributions}

The main objective of this study is to optimise the sustainability of a STHE by taking into account a large number of indicators addressing economic, social and environmental issues. An integrated optimisation method will be used for such a purpose.

On the other hand, the midpoint impact methods recommended by the International Reference Life Cycle Data System Handbook [18] were used to assess the environmental impacts. In other words, 15 environmental impact categories were taken into account. Six different sets of weights were also considered for the environmental indicators. Furthermore, two different cases (linear and non-linear) were established for assessing the economic and environmental aspects.

The optimisation was carried out by using different techniques. All of the above served to analyse how the contribution to sustainable development varies depending on the values taken by the design parameters.

The reminder of this study is organised as follows. The reader can find in Section 2 information about the methodology used to create the different models, which are explained in Section 3, together with the case study considered. The results are shown and discussed in Section 4. Finally, the main conclusions are summarised in Section 5.

\section{Materials and Methods}

This section is divided into two different subsections. In the first one (Section 2.1) the integrated optimisation methodology used in this study is presented. The reader can find, in Section 2.2, a brief explanation of the five optimisation techniques employed to find the optimal or sub-optimal STHE design. 


\subsection{Integrated Optimisation Method}

An integrated optimisation methodology was applied. Its conceptual framework is described in del Caño et al. [19] and it was previously used in Cartelle Barros et al. [2,17]. It is based on the definition of two models. The first one is the mathematical model, in which the design and operation of the energy system are established. It must include all the variables, equations, correlations and restrictions that ensure the proper functioning of the energy system.

The second one must be based on a multicriteria-decision making method (MCDM) to assess the sustainability of each one of the designs provided by the mathematical model, by taking into account environmental, social and economic indicators.

One alternative is the Integrated Value Model for Sustainability Assessment method also known by its Spanish acronym, Modelo Integrado de Valor para una Evaluación Sostenible (MIVES) [20].

Once both models were constructed, the connection is possible (Figure 1). The inputs of the second model result from the mathematical model. In other words, each possible and valid STHE design provided by the first model has its own consumption of resources, emissions, employment generation, costs and, therefore, its own impacts and its own sustainability index (SI) that can be assessed in the MIVES one. The next step consists of carrying out an optimisation process to find the STHE design with the highest SI.

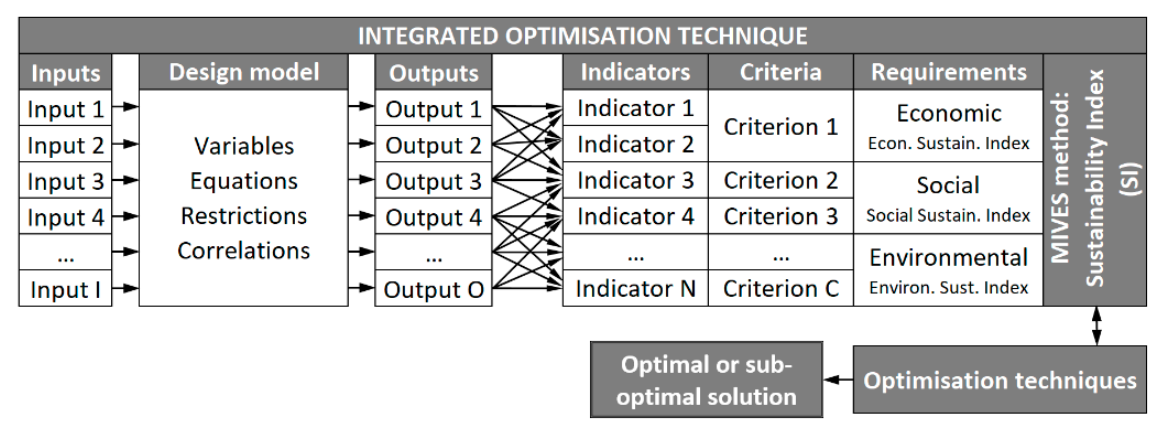

Figure 1. Flowchart of the integrated optimisation technique employed.

\subsection{Optimisation Techniques}

One of the easiest methods consists of adopting an exhaustive search approach, also known as brute force search approach [21]. Obviously, as its name suggests, it requires considerable computation power. This makes this option inapplicable as the complexity of the optimisation problem increases. The reader can find in Figure 2 a general diagram about this technique.

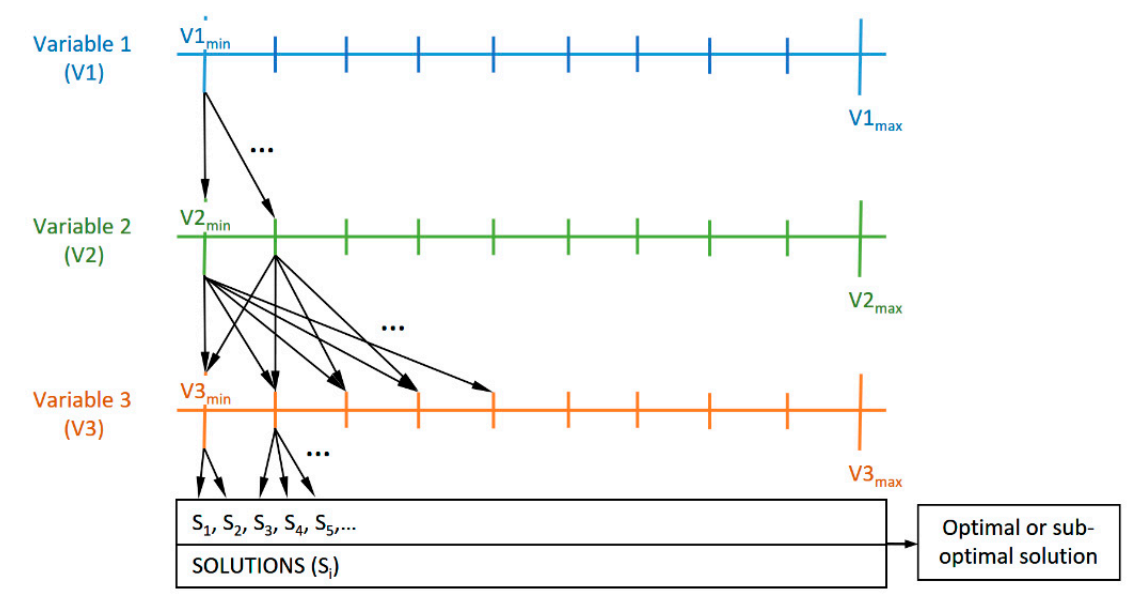

Figure 2. General diagram explaining the exhaustive search approach. 
Another simple alternative is to apply Monte Carlo simulation [22] as an optimisation algorithm [23]. In this case, a probability distribution is assigned to each one of the design variables (here, uniform distributions). After that, a simulation process is run. Once the convergence is achieved, the STHE design with the highest SI can be identified. Monte Carlo is more sophisticated than the exhaustive search approach. However, its efficiency as an optimisation algorithm is still far from other existing optimisation techniques [24].

Most of the engineering systems to be designed and optimised are complex enough to make the first two approaches inapplicable. In the same line, classical optimisation techniques will hardly be applicable if the MIVES model presents discrete value functions, something that is quite common. Under these circumstances, intelligent computation methods are likely to outperform classical techniques $[25,26]$.

Consequently, a more complex alternative is the Particle Swarm Optimisation (PSO) algorithm [27]. PSO is an optimisation algorithm that imitates the social behaviour of birds in flocks or fishes in school of fish [28].

PSO entails defining an initial population of particles, in particular both their positions (Position P $_{\text {) }}$ and velocities (Velocity $y_{i}$, that are set randomly but within the ranges allowed. Each particle (in particular, its position) represents a possible solution to the problem [28]. In other words, it is possible to assume that each position is a vector: Position $_{i}=\left(\right.$ Position $_{i, 1}$, Position $_{i, 2}$, Position $_{i, 3}, \ldots$, Position $\left._{i, N d}\right)$, where $i$ is the particle index and $N d$ is the number of design variables. In other words, the number of components coincides with the number of design variables $(N d)$. The same is also true for the velocity: Velocity $_{i}=\left(\right.$ Velocity $_{i, 1}$, Velocity $_{i, 2}$, Velocity $_{i, 3}, \ldots$, Velocity $\left._{i, N d}\right)$. The position of each one of the particles $\left(\right.$ Position $_{i}$ ) can be considered as a vector of coordinates associated with a single point in the solution space [28]. Each position is assessed through the objective function to see how each particle performs. In every iteration, the best position of each particle (Position ibest $_{\text {) }}$ as well as the best position of all particles (Global best $_{\text {) }}$ are updated, if necessary, and saved [28]. Additionally, in each iteration, all the components of the velocity $\left(\right.$ Velocity $\left._{i}\right)$ and position $\left(\right.$ Position $\left._{i}\right)$ vectors of all particles are updated [28] by using Equations (1) and (2), respectively,

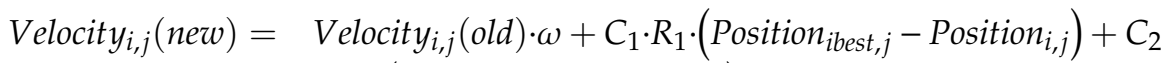

$$
\begin{aligned}
& \cdot R_{2} \cdot\left(\text { Global }_{\text {best }, j}-\text { Position }_{i, j}\right) \\
& \text { Position }_{i, j}(\text { new })=\text { Position }_{i, j}(\text { old })+\text { Velocity }_{i, j}(\text { new })
\end{aligned}
$$

where $i$ represents the particle index and $j$ represents the dimension (each one of the design variables). As can be deducted from Equation (1), the new velocity (Velocity $(n e w)$ ) is calculated from the

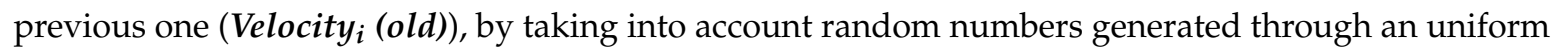
distribution $\left(R_{1}\right.$ and $\left.R_{2}\right)$, the inertial weight $(\omega)$, the acceleration coefficients $\left(C_{1}\right.$ and $\left.C_{2}\right)$, and both the

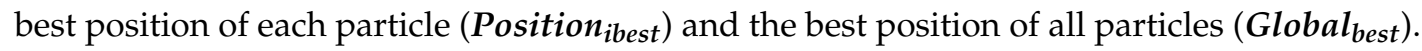

The position (Position $\left._{i}(\mathbf{n e w})\right)$ is updated from the previous position $\left(\right.$ Position $_{i}($ old $)$ ) by considering the velocity (Equation (2)). Once the termination criteria are met, the optimal solution is the last best position of all particles (the last Global $_{\text {best }}$ ). The reader can find a simplified diagram summarising the main steps of PSO in Figure 3.

Another nature-inspired optimisation technique is the Crow Search Algorithm (CSA) [29]. The CSA presents some similarities with PSO. Consequently, part of the notation used for explaining PSO will be valid for this algorithm. CSA tries to imitate the social behaviour of crows [29].

As with PSO, CSA begins with an initialisation process, in which a population of crows (positions $\left(\right.$ Position $\left._{i}\right)$; that is, possible solutions) are established randomly but within the ranges allowed. Once again, it is possible to assume that each position is a vector with a number of components equal to the number of design variables $(N d)$, being $i$ the crow index. The best position that each crow (Position $_{\text {ibest }}$ ) adopts is saved and, if necessary, updated in each iteration. To do so, all the positions are assessed throughout the objective function. The position of each crow is also updated in each iteration. Two different states are possible. 


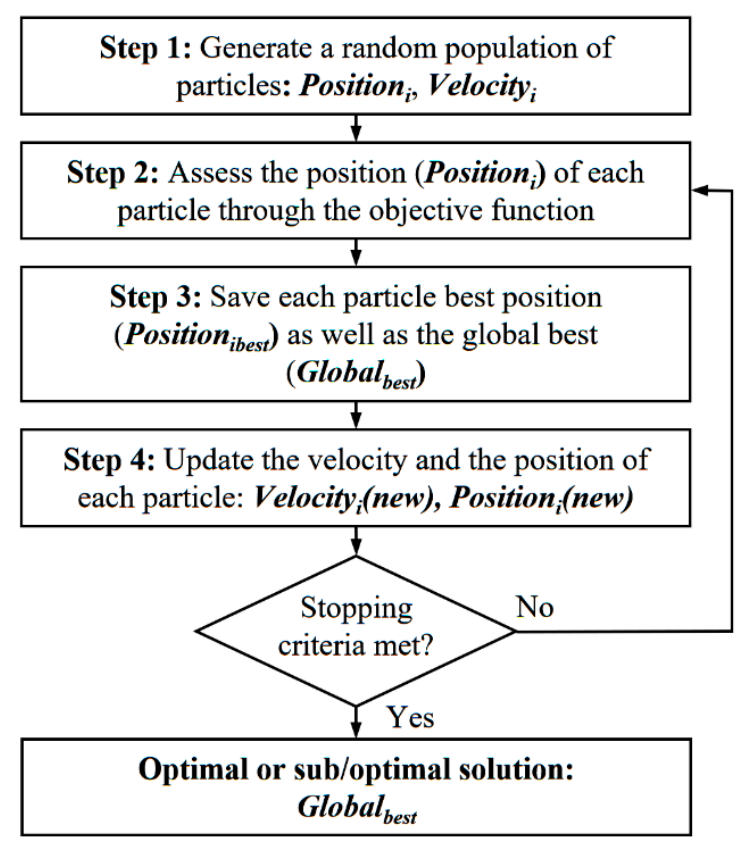

Figure 3. Flowchart explaining the main steps of the Particle Swarm Optimisation (PSO) algorithm.

In the first one, each crow (crow 1,i=1) randomly selects other crow (crow 2, $i=2$ ). The first one tries to move towards the best position the second crow has experimented so far (Position 2best $_{\text {) }}$. In such a case, each one of the components of the position vector for the first crow is updated by taking into

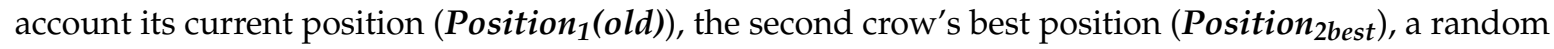
number $\left(R_{3}\right)$ generated through an uniform distribution and the flight length $(f l)$, as deducted from Equation (3).

$$
\text { Position }_{1, j}(\text { new })=\text { Position }_{1, j}(\text { old })+R_{3} \cdot f l \cdot\left(\text { Position }_{2 b e s t, j}-\text { Position }_{1, j}(\text { old })\right)
$$

Once again, $j$ represents the dimension. The second state is a particular case of the first one, in which the second crow (crow 2, $i=2$; the selected one) suspects that the first crow (crow 1,i=1) is trying to steal its food. Consequently, it flies to a random place. In other words, in the second state, the position of the first crow is updated randomly. The solution to the problem is the best position among all the best positions that the crows adopt in the last iteration. A general and simplified diagram of CSA is shown in Figure 4.

Both in PSO and CSA, different stopping criteria can be established. One option is to control how the best solution changes as the number of iterations increases.

The sustainability optimisation of an energy system can be treated as a multi-objective optimisation problem. This is because, the sustainability index (SI) is composed of three partial indices, each one of them associated with a sustainability dimension (economic (EI), social (SOI) and environmental (ENI)) as can be seen in Table 1. Therefore, multi-objective genetic algorithms are also applicable, such as the Non Dominated Sorting Genetic Algorithm II (NSGA-II) [30]. As it is a multi-objective technique, the solution will be a set of optimal solutions (Pareto optimal) instead of a single one [30]. In this case, the starting point is the same, that is, a population of $N$ possible solutions (individuals) that are defined randomly. All the individuals are classified into different levels on the basis of non-dominance [30]. After that, a selection process is carried out, where the best individuals are chosen in a tournament selection. The selected individuals will be the parents to the next generation of individuals. The next generation of individuals is the result of a combined process of crossover and mutation. At this time, there is an intermediate population that is the combination between the parents and the new individuals. This intermediate population is sorted, once again according to the non-dominance criterion, and the best $N$ individuals are selected. This process is repeated until the maximum number 
of generations is reached. In this case, the selected design (solution) will be the one with the highest $S I$. The reader can find in Figure 5 a general flowchart with the main steps of NSGA-II.

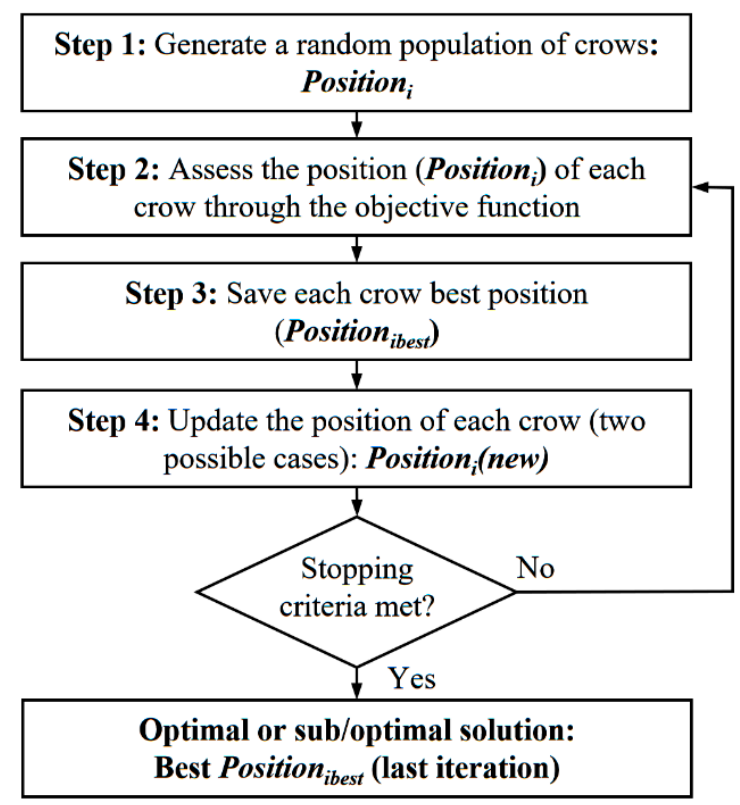

Figure 4. Flowchart explaining the main steps of the Crow Search Algorithm (CSA) algorithm.

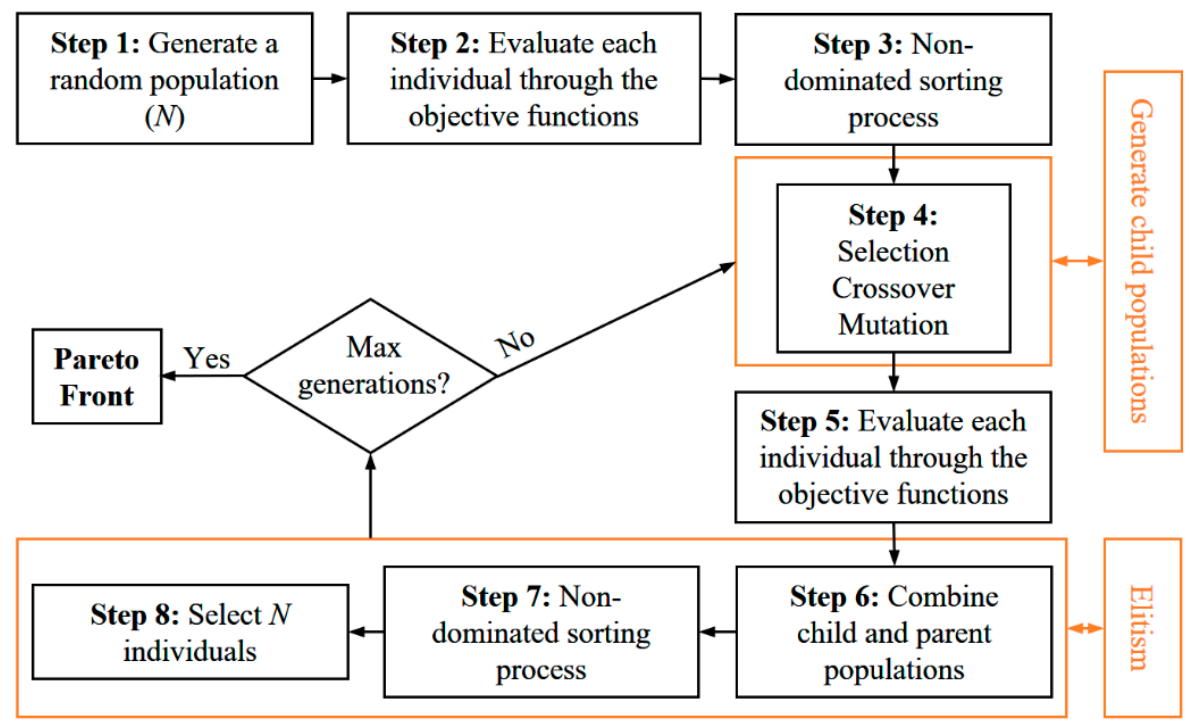

Figure 5. Non-Dominated Sorting Genetic Algorithm II (NSGA-II) main steps.

There are many other optimisation techniques that could have been implemented. The necessity of trying different algorithms is due to the fact that there is no one that outperforms all the remaining alternatives in all cases [25].

\section{Models}

\subsection{Mathematical Model}

The mathematical model is linked to the case study to be solved since different equations are used depending on some of the STHE characteristics. Therefore, it is first necessary to provide some general information on the case study. In particular, it consists of designing a STHE to sub-cool condensate from a methanol (shell side) condenser (from 368.15 to $313.15 \mathrm{~K}$ ) by using brackish water (tube side) 
as coolant (with a 15-degree increase in temperature from $298.15 \mathrm{~K}$ ). Stainless steel type 316 is used. The STHE will have an equilateral triangular pitch arrangement, with one shell pass and two tube passes. Three optimisation variables were used: the shell internal diameter $\left(D_{s}\right)$, the tube external diameter $\left(d_{0}\right)$ and the baffle distance $(B)$, varying between 0.1 and $1.15 \mathrm{~m}, 0.008$ and 0.05 , and 0.05 and $0.5 \mathrm{~m}$, respectively. The Logarithmic Mean Temperature Difference (LMTD) method was used, since the fluid inlet and outlet temperatures are known. The reader can find in [17] all the necessary information associated with the mathematical model, as well as the tube side and shell side specifications. Both the nomenclature and the parameters are equivalent.

In this case, a limit of 25,000 Pa was established both for the tube side and shell side pressure drops. Additionally, the baffle distance $(B)$ must be smaller than the value adopted by the shell internal diameter $\left(D_{s}\right)$. On the other hand, $B$ must be larger than one fifth of $D_{s}$. All the designs that do not fulfil all the restrictions fixed will not be considered as possible solutions to the optimisation problem.

\subsection{MIVES Model}

A MIVES model comprising 19 indicators was used to assess the sustainability of each valid design (Table 1). From the 19 indicators, one belongs to the economic dimension of sustainability (Total Cost, C1), three belong to the social one (S1-S3), while the remaining ones quantify different environmental impacts (E1-E15), in particular, the ones recommended by the International Reference Life Cycle Data System Handbook [18], with only one exception, which will be explained later.

Table 1. Requirement tree of the Modelo Integrado de Valor para una Evaluación Sostenible (MIVES) model. Environmental criteria weights based on [31].

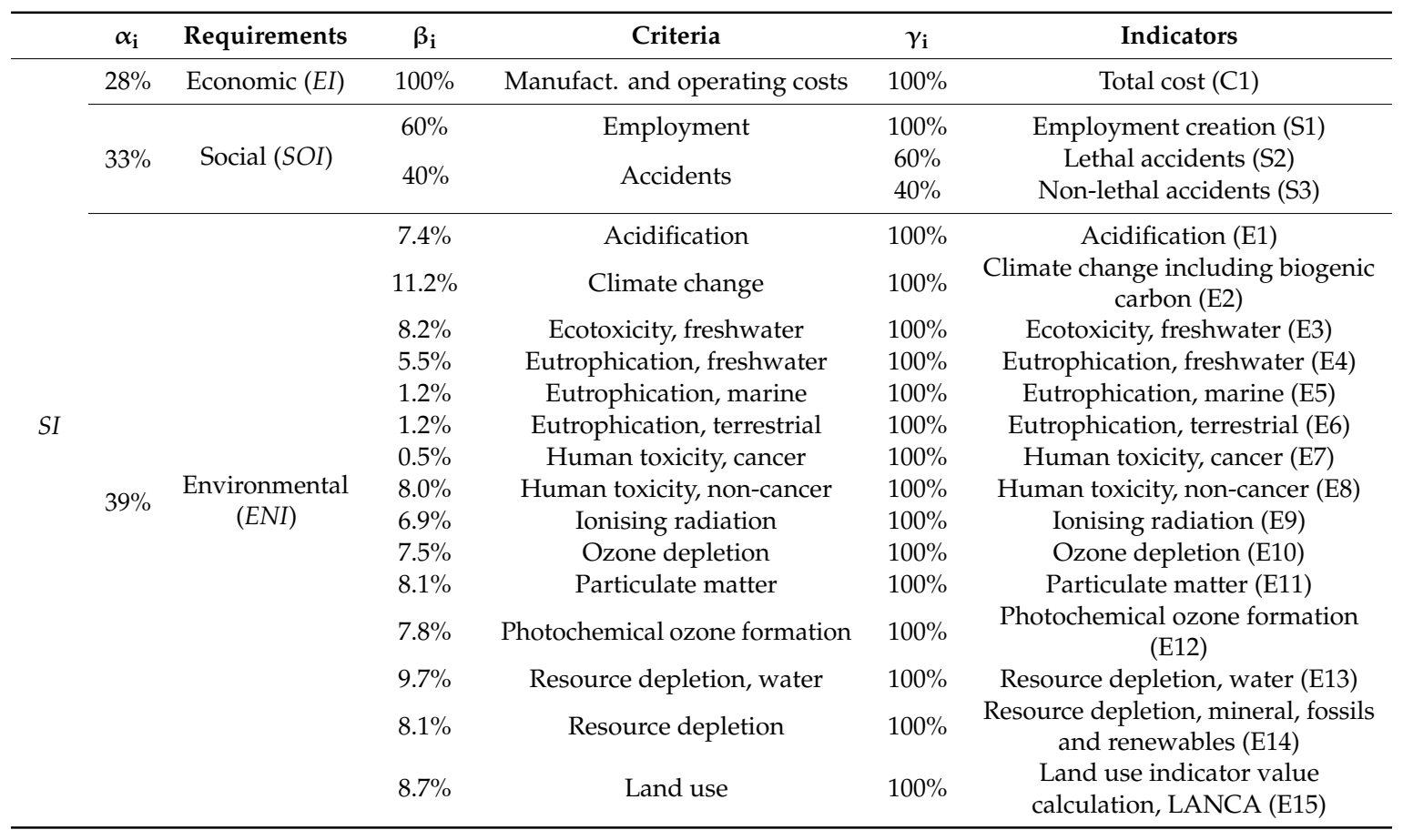

The sustainability index (SI) of each STHE is calculated through Equation (4) [32]. The partial sustainability indices (EI, SOI and ENI) can be estimated by applying Equation (4) but, this time, only using the criteria and indicators belonging to each of the sustainability dimensions.

$$
S I=\sum_{i=1}^{19} \alpha_{i} \cdot \beta_{i} \cdot \gamma_{i} \cdot V_{i}
$$


SI is the objective function and falls within the interval [0,1], with 0 and 1 being the worst and best possible solutions, respectively. $\alpha_{i}, \beta_{i}$, and $\gamma_{i}$ are the weights for the requirements, criteria and indicators, respectively (Table 1). $V_{i}$ are the value functions used to assess the performance of each valid STHE with regard to each indicator. Once again, $V_{i}$ only takes values from 0 to 1 , the worst and best possible answers, respectively. This is estimated through Equation (5) [32]:

$$
V_{i}=\frac{1-\exp \left(-m_{i} \cdot\left(\frac{\left|P_{i}-P_{i, \text { min }}\right|}{n_{i}}\right)^{A_{i}}\right)}{1-\exp \left(-m_{i} \cdot\left(\frac{\left|P_{i, \text { max }}-P_{i, \text { min }}\right|}{n_{i}}\right)^{A_{i}}\right)}
$$

In the previous equation, $P_{i}$ is the input value of a STHE design for a specific indicator. $P_{i, \min }$ and $P_{i, \max }$ are the input values to the value functions that generate the minimum and maximum levels of satisfaction, 0 and 1 , respectively. $A_{i}, n_{i}$ and $m_{i}$ are shape factors that make it possible to construct value functions with different geometries (convex, concave, linear, among others). In this study, two different cases were considered in relation to value functions. In the first one, the linear case (L), all value functions are linear. In the second case, the non-linear one (NL), both linear and non-linear geometries were defined for the value functions. In fact, all value functions were defined as non-linear ones, with the exception of social indicators. The parameters both for the linear and the non-linear cases are shown in Table 2.

Table 2. Parameters for the value functions both for the linear (L) and non-linear (NL) cases.

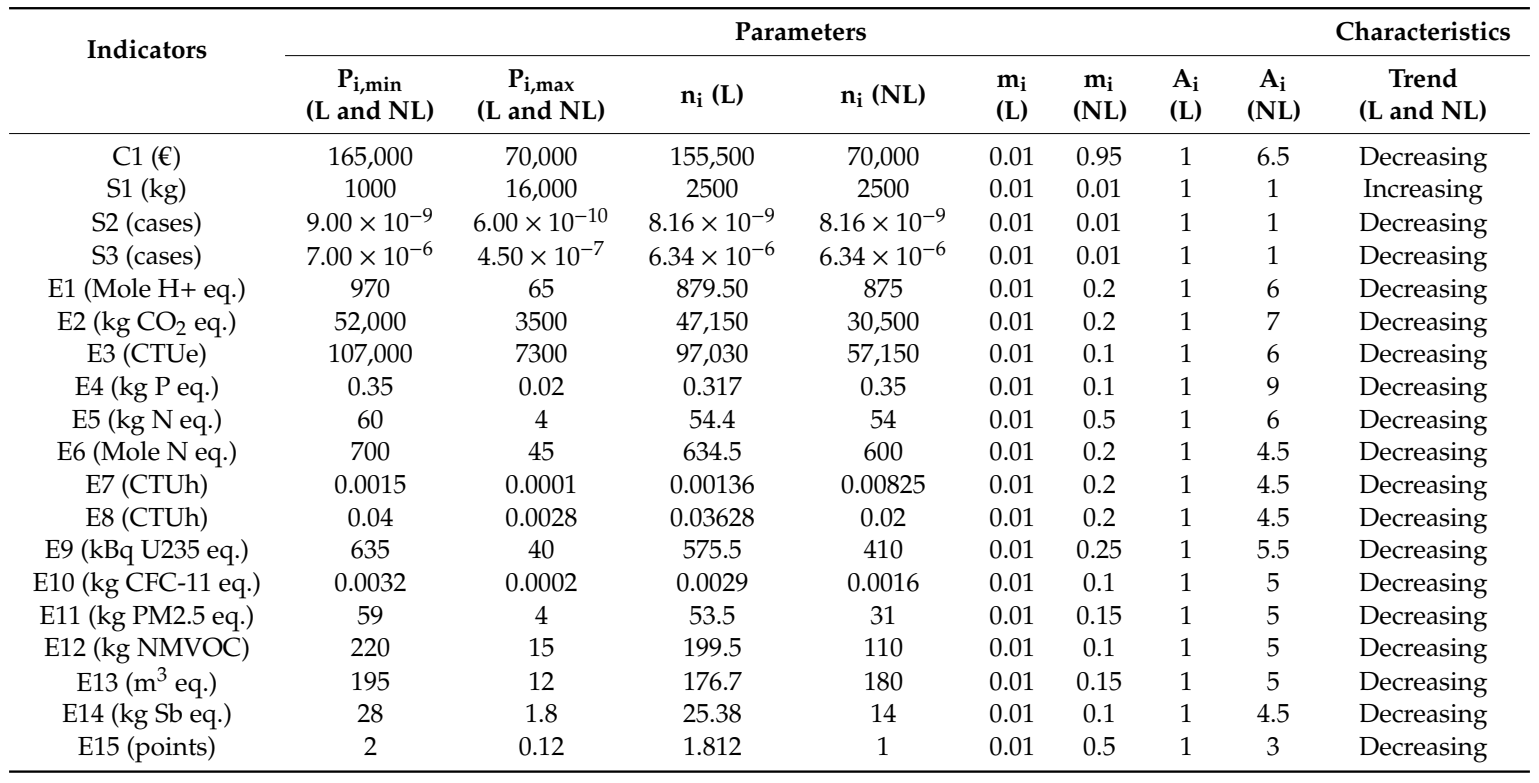

It is now necessary to clarify how the input values to the MIVES model for the different indicators were calculated. The units of measurement are contained in Table 2.

The total cost $(C 1)$ comprises both the capital investment $\left(C_{i n v}\right)$ and the total operating discounted $\operatorname{cost}\left(C_{\text {odc }}\right)[17]$ :

$$
C 1=C_{i n v}+C_{o d c}
$$

The total operating discounted $\operatorname{cost}\left(C_{o d c}\right)$ is estimated through the following equation [17]

$$
C_{o d c}=\sum_{i=1}^{n_{\text {years }}} \frac{C_{a o c}}{(1+d)^{i}}
$$


where $n_{\text {years }}$ is the useful life of the STHE ( $n_{\text {years }}=10$ years in this case), $d$ is the annual discount rate (here assumed as $d=0.1$ ) and $C_{a o c}$ is the annual operating cost [17]:

$$
C_{a o c}=P_{p} \cdot C_{e} \cdot H
$$

In Equation (8), $P_{p}$ is the required pumping power $(\mathrm{W})$ [17]. $C_{e}$ is the energy cost, and here takes a value of $0.00012 € / \mathrm{Wh}$. $H$ is the annual operating time and a value of $7000 \mathrm{~h} /$ year was established.

There are different methods that can be used to estimate the capital investment cost of a STHE [33,34]. In this case, Hall's correlation [34] was used, since it is not time-consuming and it was widely used in the existing literature [11-17,35-42], with promising results [34]

$$
C_{i n v}=a_{1}+a_{2} \cdot A^{a_{3}}
$$

where $A$ is the STHE surface area in $\mathrm{m}^{2}$, and $a_{1}(€), a_{2}\left(€ / \mathrm{m}^{2}\right)$ and $a_{3}$ are numerical constants that depend on the material employed. The same values proposed in [17] were used here.

The inputs for the social and environmental indicators are estimated from the amount of stainless steel in $\mathrm{kg}(M)$ employed in the tubes of each valid design. For such a purpose the following equation is used [17]

$$
\text { Social_Environmental }{ }_{i}=\text { Factor }_{i} \cdot M
$$

In Equation (10) Factor ${ }_{i}$ represents the social and environmental factors linked to the production of $1 \mathrm{~kg}$ of 316 stainless steel (Table 3). These factors were extracted from [43]. The employment creation (S1) is an exception to the use of Equation (10). In this case, it was assumed that the employment generation varies with the amount of stainless steel consumed in each design. Therefore, S1 is directly assessed from the mass of stainless steel $(M)$. This assumption was also considered in [17].

Table 3. Factors associated with $1 \mathrm{~kg}$ of 316 stainless steel.

\begin{tabular}{cc}
\hline Indicators & Social and Environmental Factors \\
\cline { 2 - 2 } Lethal accidents (S2, cases) & Factor \\
\hline Non-lethal accidents (S3, cases) & $5.68 \times 10^{-13}$ \\
Acidification (E1, Mole H+ eq.) & $4.35 \times 10^{-10}$ \\
Climate change including biogenic carbon (E2, kg CO eq. $^{\text {. }}$ & $5.9 \times 10^{-2}$ \\
Ecotoxicity, freshwater (E3, CTUe) & 3.17 \\
Eutrophication, freshwater (E4, kg P eq.) & 6.55 \\
Eutrophication, marine (E5, kg N eq.) & $2.17 \times 10^{-5}$ \\
Eutrophication, terrestrial (E6, Mole N eq.) & $3.82 \times 10^{-3}$ \\
Human toxicity, cancer (E7, CTUh) & $4.28 \times 10^{-2}$ \\
Human toxicity, non-cancer (E8, CTUh) & $9.43 \times 10^{-8}$ \\
Ionising radiation (E9, kBq U235 eq.) & $2.54 \times 10^{-6}$ \\
Ozone depletion (E10, kg CFC-11 eq.) & $3.9 \times 10^{-2}$ \\
Particulate matter (E11, kg PM2.5 eq.) & $1.97 \times 10^{-7}$ \\
Photochemical ozone formation (E12, kg NMVOC) & $3.63 \times 10^{-3}$ \\
Resource depletion, water (E13, m ${ }^{3}$ eq.) & $1.35 \times 10^{-2}$ \\
Resource depletion, mineral, fossils and renewables (E14, kg Sb eq.) & $1.2 \times 10^{-2}$ \\
Land use indicator value calculation, LANCA (E15, points) & $1.7 \times 10^{-3}$ \\
\hline
\end{tabular}

The reader can find more information in the ILCD handbook about the environmental indicators [18]. The impacts associated with land use (E15) were assessed by using the Land Use Indicator Value Calculation in Life Cycle Assessment (LANCA) indicator that is not the one recommended by the ILCD handbook. This is because LANCA is probably the most complete indicator in terms of land use impacts. The reader can find more information about the different indicators used 
to assess the land use impacts in Vidal-Legaz et al. [44]. It is also necessary to clarify that LANCA is measured in points, which is an aggregated result from the LANCA original indicator.

One of the steps of the MIVES method involves defining the weights of the requirements, criteria and indicators. The weights proposed in Cartelle Barros et al. [17] were used in this case for the requirements, the social criteria and indicators, and for the economic criteria and indicators. On the other hand, for the environmental criteria, different sets of weights were considered. One set of weights is included in Table 1, while the remaining are shown in Table 4.

Table 4. Different sets of weights for the environmental criteria.

\begin{tabular}{cccccc}
\hline Criteria & \multicolumn{3}{c}{ Sets of Weights $\left(\boldsymbol{\beta}_{\boldsymbol{i}}\right)$} \\
\cline { 2 - 6 } & Equal & $\begin{array}{c}\text { Ref. [45] } \\
\text { (Binding } \\
\text { Targets) }\end{array}$ & $\begin{array}{c}\text { Ref. [45] (Binding } \\
\text { and Non-Binding } \\
\text { Targets) }\end{array}$ & $\begin{array}{c}\text { Refs. } \\
{[45,46]}\end{array}$ & $\begin{array}{c}\text { Ref. } \\
{[47]}\end{array}$ \\
\hline Acidification & $6.67 \%$ & $7.2 \%$ & $5.5 \%$ & $4.2 \%$ & $4.2 \%$ \\
Climate change & $6.67 \%$ & $7.1 \%$ & $5.4 \%$ & $23.2 \%$ & $23.2 \%$ \\
Ecotoxicity, freshwater & $6.67 \%$ & $6.4 \%$ & $5.3 \%$ & $10.9 \%$ & $10.9 \%$ \\
Eutrophication, freshwater & $6.67 \%$ & $6.2 \%$ & $4.7 \%$ & $5.0 \%$ & $2.3 \%$ \\
Eutrophication, marine & $6.67 \%$ & $6.9 \%$ & $5.2 \%$ & $1.0 \%$ & $2.3 \%$ \\
Eutrophication, terrestrial & $6.67 \%$ & $7.0 \%$ & $5.3 \%$ & $1.0 \%$ & $2.3 \%$ \\
Human toxicity, cancer & $6.67 \%$ & $6.9 \%$ & $5.2 \%$ & $6.5 \%$ & $6.5 \%$ \\
Human toxicity, non-cancer & $6.67 \%$ & $6.2 \%$ & $4.7 \%$ & $4.1 \%$ & $4.1 \%$ \\
Ionising radiation & $6.67 \%$ & $6.1 \%$ & $4.6 \%$ & $6.5 \%$ & $6.5 \%$ \\
Ozone depletion & $6.67 \%$ & $6.4 \%$ & $4.8 \%$ & $3.6 \%$ & $3.6 \%$ \\
Particulate matter & $6.67 \%$ & $7.4 \%$ & $5.6 \%$ & $6.6 \%$ & $6.6 \%$ \\
Photochemical ozone formation & $6.67 \%$ & $7.8 \%$ & $5.9 \%$ & $5.4 \%$ & $5.4 \%$ \\
Resource depletion, water & $6.67 \%$ & $6.1 \%$ & $29.6 \%$ & $5.1 \%$ & $5.1 \%$ \\
Resource depletion & $6.67 \%$ & $6.1 \%$ & $3.0 \%$ & $6.9 \%$ & $6.9 \%$ \\
Land use & $6.67 \%$ & $6.2 \%$ & $5.2 \%$ & $10.0 \%$ & $10.1 \%$ \\
\hline
\end{tabular}

As can be seen from Tables 1 and 4, there is no unanimity at the time of establishing the relative importance of the different environmental impacts. Therefore, by solving the same optimisation problem with different sets of weights, it will be possible to discuss how the results (the design of the STHE) are affected.

\section{Results and Discussions}

Some general comments are needed before discussing the results. It must be clear to the reader how the results change (SI, EI, SOI and ENI) depending on the variation that some parameters experiment. As explained in previous sections, the Sustainability Index $(S I)$ varies between 0 and 1 , minimum and maximum levels of satisfaction. It also consists of three partial indices (economic (EI), social (SOI) and environmental $(E N I)$ ). According to Table 1, these partial indices vary between 0 and 0.28 , between 0 and 0.33 , and between 0 and 0.39 , respectively. Optimising the $S I$ is not equal to optimise each one of the partial indices separately, since there are conflicts between the indicators.

Regarding the economic dimension, there is only one indicator for assessing the total life cycle costs of each STHE design. Nevertheless, this indicator consists of two main components: investment costs $\left(C_{i n v}\right)$ and the total operating costs $\left(C_{o d c}\right) . C_{i n v}$ depends on the STHE surface area $(A)$. Consequently, minimising $A$ is equivalent to minimising the investment costs $\left(C_{i n v}\right)$. Nevertheless, the minimum investment cost is not necessarily associated with the minimum operating costs $\left(C_{o d c}\right)$. The reader can verify this statement by comparing some of the different cases presented in Tables $5-8$. The operating costs increase with the shell side and tube side pressure drops, since more pumping power $P_{p}$ is needed to overcome friction losses. The pressure drop increases as the fluid velocity and tube length increase. The opposite occurs with the tube internal diameter and with the equivalent one. For the particular case of the shell side pressure drop, the baffle distance $(B)$ as well as the shell internal diameter $\left(D_{s}\right)$ also 
come into play. Consequently, one may think that by minimising the total pressure drop, the optimum operating cost $\left(C_{o d c}\right)$ must be obtained. It is possible to say that this idea is true in a general context. However, there can be specific cases in which a lower value of total pressure drop is not associated with a lower operating cost $\left(C_{o d c}\right)$. This is due to the role that densities and mass flow rates play. After analysing the results presented in Tables $5-8$, one realises that, in the case study considered in this paper, the capital investment $\left(C_{i n v}\right)$ is more important than the total operating costs $\left(C_{o d c}\right)$, since the first one is considerably higher than the second one. Consequently, the minimisation of the capital investment will prevail over the operating costs minimisation, whether the SI or the EI is optimised.

In the case of the social pillar, the requirement tree is made up of three indicators. Two of them are associated with possible accidents, while the remaining one assesses the employment generation potential. The three indicators depend on the amount of material $(M)$. However, they do not follow the same trend, since a higher value of $M$ implies a better performance in terms of employment creation, while the opposite occurs for the accidents. Therefore, it is possible to say that optimising the SOI is not equivalent to optimising each one of the indicators separately. As a result, the optimal STHE designs will not achieve strong results from a social point of view (far from the maximum: 0.33 ). On the other hand, it is important to note that the minimisation of two physical magnitudes $(A$ and $M)$ is associated with a better performance in terms of capital investment and accidents, respectively. At first sight, one may think that a higher value of $A$ is always equivalent to a higher value of $M$. Nevertheless, there are specific examples in which a higher value of $A$ implies a lower value of $M$. It can therefore be said that optimising a part of the social index (SOI), in particular the results for the accidents, are, to some extent, linked to optimising the most relevant parameter $\left(C_{i n v}\right)$ of the economic dimension.

With regard to the environmental dimension, all the indicators depend on the amount of material $(M)$. Furthermore, all of them present the same behaviour: a lower value of $M$ generates a better performance (less significant environmental impact). Optimising the environmental index (ENI) implies an optimisation of a part of the social dimension, in particular the one related to accidents. Similarly, optimising the ENI will not generate good results in terms of job creation, since these two aspects are in conflict. It is also possible to say that, to a certain extent, minimising the environmental impacts will generally result in a lower capital investment.

The main objective of this study is to maximise the contribution of the STHE under design to the sustainable development. As is clear from previous paragraphs, this is not an easy task, since the mathematical model is complex and different conflicts arise. Despite this, it is possible to intuit what is going to happen with the partial sub-indices when the sustainability index (SI) is maximised. To this end, consideration must be given to the relative importance of the requirements in Table 1 . The most important dimension of sustainability is the environmental one (39\%). Regardless of the case, weights and optimisation technique, each one of the optimal or sub-optimal designs should present an environmental index (ENI) close to the maximum (0.39), when the SI is optimised. The reader can confirm this statement by looking at Tables 5-7. On the other hand, it has been explained that optimising the environmental dimension will usually lead to cost-effective solutions in terms of capital investment. As shown in Tables 5 and 6, the economic indices (EI) linked to the optimal or sub-optimal solutions are close to the maximum possible value (0.28), which confirms the previous statement. Finally, when the SI is maximised, the corresponding social index (SOI) is not expected to be close to the possible maximum value (0.33). Consequently, the optimal or sub-optimal designs will present SOIs placed in half the way between the minimum and maximum possible values. In particular, the chosen solutions will be the ones that generate a reasonably high $S O I$ without unduly penalising the other two dimensions of sustainability. In fact, the SOIs contained in Tables 5 and 6 take values around 0.13 .

\subsection{Comparisons among the Different Cases}

Table 5 contains some of the most important results for the different sets of weights for the first case (linear value functions, $\mathrm{L}$ ). 
Table 5. Results for Case 1 (linear value functions, L).

\begin{tabular}{|c|c|c|c|c|c|c|c|}
\hline \multirow[b]{2}{*}{$\begin{array}{l}\text { Optimisation } \\
\text { Techniques }\end{array}$} & \multirow{2}{*}{$\begin{array}{l}\text { Variables, } \\
\text { Parameters } \\
\text { and Indices }\end{array}$} & \multicolumn{6}{|c|}{ Sets of Weights $\left(\beta_{i}\right)$} \\
\hline & & $\begin{array}{c}\text { Reference } \\
\text { [31] }\end{array}$ & Equal & $\begin{array}{l}\text { Ref. [45] } \\
\text { (Binding } \\
\text { Targets) }\end{array}$ & $\begin{array}{c}\text { Ref. [45] (Binding } \\
\text { and Non-Binding } \\
\text { Targets) }\end{array}$ & $\begin{array}{c}\text { References } \\
{[45,46]}\end{array}$ & $\begin{array}{c}\text { Reference } \\
\text { [47] }\end{array}$ \\
\hline \multirow{12}{*}{$\begin{array}{l}\text { Exhaustive } \\
\text { search }\end{array}$} & $D_{S}(\mathrm{~m})$ & 0.7152 & 0.7152 & 0.7152 & 0.7152 & 0.7152 & 0.7152 \\
\hline & $d_{0}(\mathrm{~m})$ & 0.0080 & 0.0080 & 0.0080 & 0.0080 & 0.0080 & 0.0080 \\
\hline & $B(\mathrm{~m})$ & 0.5000 & 0.5000 & 0.5000 & 0.5000 & 0.5000 & 0.5000 \\
\hline & $A\left(\mathrm{~m}^{2}\right)$ & 222.49 & 222.49 & 222.49 & 222.49 & 222.49 & 222.49 \\
\hline & $M(\mathrm{~kg})$ & 1281.5 & 1281.5 & 1281.5 & 1281.5 & 1281.5 & 1281.5 \\
\hline & $C_{i n v}(€)$ & 67,356 & 67,356 & 67,356 & 67,356 & 67,356 & 67,356 \\
\hline & $C_{o d c}(€)$ & 9174 & 9174 & 9174 & 9174 & 9174 & 9174 \\
\hline & $C 1(€)$ & 76,530 & 76,530 & 76,530 & 76,530 & 76,530 & 76,530 \\
\hline & $E I$ & 0.2608 & 0.2608 & 0.2608 & 0.2608 & 0.2608 & 0.2608 \\
\hline & SOI & 0.1338 & 0.1338 & 0.1338 & 0.1338 & 0.1338 & 0.1338 \\
\hline & ENI & 0.3840 & 0.3839 & 0.3840 & 0.3837 & 0.3841 & 0.3842 \\
\hline & SI & 0.7786 & 0.7785 & 0.7786 & 0.7783 & 0.7787 & 0.7788 \\
\hline \multirow{12}{*}{ Monte Carlo } & $D_{s}(\mathrm{~m})$ & 0.7226 & 0.7396 & 0.7200 & 0.7220 & 0.7020 & 0.7406 \\
\hline & $d_{0}(\mathrm{~m})$ & 0.0080 & 0.0080 & 0.0080 & 0.0081 & 0.0080 & 0.0080 \\
\hline & $B(\mathrm{~m})$ & 0.4774 & 0.4892 & 0.4890 & 0.4883 & 0.4912 & 0.4930 \\
\hline & $A\left(\mathrm{~m}^{2}\right)$ & 222.21 & 226.29 & 222.66 & 223.09 & 219.47 & 226.89 \\
\hline & $M(\mathrm{~kg})$ & 1282.1 & 1304.9 & 1286.6 & 1293.3 & 1266.2 & 1313.1 \\
\hline & $C_{i n v}(€)$ & 67,294 & 68,210 & 67,394 & 67,490 & 66,677 & 68,345 \\
\hline & $C_{o d c}(€)$ & 9396 & 8330 & 9219 & 9149 & 10,089 & 8206 \\
\hline & $C 1(€)$ & 76,690 & 76,540 & 76,613 & 76,639 & 76,766 & 76,551 \\
\hline & $E I$ & 0.2603 & 0.2608 & 0.2606 & 0.2605 & 0.2601 & 0.2607 \\
\hline & SOI & 0.1338 & 0.1339 & 0.1338 & 0.1338 & 0.1337 & 0.1339 \\
\hline & ENI & 0.3840 & 0.3833 & 0.3839 & 0.3834 & 0.3844 & 0.3835 \\
\hline & $S I$ & 0.7781 & 0.7780 & 0.7783 & 0.7777 & 0.7784 & 0.7781 \\
\hline \multirow{12}{*}{ PSO } & $D_{S}(\mathrm{~m})$ & 0.7151 & 0.7151 & 0.7151 & 0.7151 & 0.7151 & 0.7151 \\
\hline & $d_{0}(\mathrm{~m})$ & 0.0080 & 0.0080 & 0.0080 & 0.0080 & 0.0080 & 0.0080 \\
\hline & $B(\mathrm{~m})$ & 0.5000 & 0.5000 & 0.5000 & 0.5000 & 0.5000 & 0.5000 \\
\hline & $A\left(\mathrm{~m}^{2}\right)$ & 222.48 & 222.48 & 222.48 & 222.48 & 222.48 & 222.48 \\
\hline & $M(\mathrm{~kg})$ & 1281.5 & 1281.5 & 1281.5 & 1281.5 & 1281.5 & 1281.5 \\
\hline & $C_{i n v}(€)$ & 67,355 & 67,355 & 67,355 & 67,355 & 67,355 & 67,355 \\
\hline & $C_{o d c}(€)$ & 9175 & 9175 & 9175 & 9175 & 9175 & 9175 \\
\hline & $C 1(€)$ & 76,530 & 76,530 & 76,530 & 76,530 & 76,530 & 76,530 \\
\hline & $E I$ & 0.2608 & 0.2608 & 0.2608 & 0.2608 & 0.2608 & 0.2608 \\
\hline & SOI & 0.1338 & 0.1338 & 0.1338 & 0.1338 & 0.1338 & 0.1338 \\
\hline & ENI & 0.3840 & 0.3839 & 0.3840 & 0.3837 & 0.3841 & 0.3842 \\
\hline & $S I$ & 0.7786 & 0.7785 & 0.7786 & 0.7783 & 0.7787 & 0.7788 \\
\hline \multirow{12}{*}{ CSA } & $D_{S}(\mathrm{~m})$ & 0.7166 & 0.7165 & 0.7177 & 0.7169 & 0.7178 & 0.7178 \\
\hline & $d_{0}(\mathrm{~m})$ & 0.0081 & 0.0081 & 0.0081 & 0.0080 & 0.0081 & 0.0080 \\
\hline & $B(\mathrm{~m})$ & 0.4942 & 0.4970 & 0.4889 & 0.4927 & 0.4904 & 0.4881 \\
\hline & $A\left(\mathrm{~m}^{2}\right)$ & 222.67 & 222.84 & 222.41 & 222.34 & 222.52 & 222.25 \\
\hline & $M(\mathrm{~kg})$ & 1296.5 & 1296.3 & 1292.4 & 1283.4 & 1291.8 & 1287.0 \\
\hline & $C_{i n v}(€)$ & 67,398 & 67,436 & 67,338 & 67,322 & 67,363 & 67,302 \\
\hline & $C_{o d c}(€)$ & 9274 & 9206 & 9349 & 9270 & 9300 & 9357 \\
\hline & $C 1(€)$ & 76,672 & 76,642 & 76,687 & 76,592 & 76,663 & 76,659 \\
\hline & $E I$ & 0.2604 & 0.2605 & 0.2603 & 0.2606 & 0.2604 & 0.2604 \\
\hline & SOI & 0.1338 & 0.1338 & 0.1338 & 0.1338 & 0.1338 & 0.1338 \\
\hline & ENI & 0.3837 & 0.3836 & 0.3837 & 0.3837 & 0.3839 & 0.3841 \\
\hline & $S I$ & 0.7779 & 0.7779 & 0.7779 & 0.7781 & 0.7781 & 0.7783 \\
\hline \multirow{12}{*}{ NSGA-II } & $D_{S}(\mathrm{~m})$ & 0.7336 & 0.7335 & 0.7336 & 0.7340 & 0.7338 & 0.7270 \\
\hline & $d_{0}(\mathrm{~m})$ & 0.0080 & 0.0080 & 0.0080 & 0.0080 & 0.0080 & 0.0080 \\
\hline & $B(\mathrm{~m})$ & 0.5000 & 0.5000 & 0.5000 & 0.5000 & 0.5000 & 0.4973 \\
\hline & $A\left(\mathrm{~m}^{2}\right)$ & 225.94 & 225.93 & 225.94 & 226.02 & 225.99 & 224.70 \\
\hline & $M(\mathrm{~kg})$ & 1301.4 & 1301.3 & 1301.4 & 1301.9 & 1301.7 & 1294.3 \\
\hline & $C_{i n v}(€)$ & 68,132 & 68,129 & 68,132 & 68,150 & 68,142 & 67,853 \\
\hline & $C_{o d c}(€)$ & 8329 & 8332 & 8329 & 8310 & 8318 & 8616 \\
\hline & $C 1(€)$ & 76,461 & 76,461 & 76,461 & 76,460 & 76,460 & 76,469 \\
\hline & $E I$ & 0.2610 & 0.2610 & 0.2610 & 0.2610 & 0.2610 & 0.2610 \\
\hline & SOI & 0.1339 & 0.1339 & 0.1339 & 0.1339 & 0.1339 & 0.1338 \\
\hline & ENI & 0.3835 & 0.3834 & 0.3835 & 0.3832 & 0.3836 & 0.3839 \\
\hline & SI & 0.7784 & 0.7783 & 0.7784 & 0.7781 & 0.7785 & 0.7787 \\
\hline
\end{tabular}


In terms of sets of weights, there are no big differences among the six options considered, not only in the SI, where the differences appear in the third decimal, reaching a maximum value of 0.0011 , but also in the values adopted by the optimisation variables. $D_{s}$ varies between 0.70 and $0.74 \mathrm{~m}$. Something similar happens with $d_{0}$ and $B$, varying from 0.008 to $0.0081 \mathrm{~m}$, and from 0.48 to $0.50 \mathrm{~m}$, respectively. This also applies to the partial indices (EI, SOI and $E N I)$, since the differences are also found in the third and fourth decimals. The amount of material hardly changes among the six cases. In fact, the highest variation occurs when Monte Carlo is used and it takes a value of $13.1 \mathrm{~kg}$ of stainless steel, which can be considered as insignificant in comparison with about $1200 \mathrm{~kg}$ for the STHE design. The total cost (C1) experiments the highest variation when CSA is used and the difference reaches a value of $226 €$. Once again, this value is negligible. Although important differences are not found in the total cost (C1), greater variations appear if one compares only the capital investment $\left(C_{i n v}\right)$ and the total discounted operating costs $\left(C_{o d c}\right)$, separately. These variations are founded on small differences in the optimisation variables and, consequently, on small differences in the fluid velocities, pressure drops, tube length, etc. Nevertheless, from the integral sustainability point of view, they are not important. In other words, two similar designs can generate a comparable total cost and a similar SI even if there are differences affecting some of their constructive parameters.

On the other hand, at the time of constructing the real STHE, the different sets of weights would lead to the same design, since normalised values are always preferable to avoid cost overruns.

Regarding the optimisation techniques, all of them provided very similar SIs, being the exhaustive search and PSO the best ones, with a slight advantage over the other options. In fact, these two techniques generate the same optimal design $\left(D_{s}=0.7151, d_{0}=0.008\right.$ and $\left.B=0.5 \mathrm{~m}\right)$. The difference among the techniques for the different sets of weights varies between 0.0006 and 0.0007 , in terms of SI. Differences in the fourth decimal can be considered as negligible. In fact, to place value on the techniques employed, the smallest SIs were also collected, with 0.33 being the minimum one. It is also important to note that big differences in the computation times were not find. This is because the current case study is a simple one in terms of number of optimisation variables. Once again, big differences were not found in the design parameters $\left(D_{s}, d_{0}\right.$ and $\left.B\right)$ and in the partial indices ( $E I, S O I$ and $E N I$ ) among the optimisation algorithms. Consequently, important differences did not occur in the remaining parameters. The difference in $M$ among the optimisation techniques varies between 19.9 and $35.5 \mathrm{~kg}$. Once again the variation is not relevant, since more than $1200 \mathrm{~kg}$ is employed in the manufacturing process of the optimal or sub-optimal solutions.

The results for the different sets of weights for the second case (non-linear value functions, NL) are shown in Table 6. In this case, only the ones obtained with the exhaustive search approach are presented, although all the optimisation techniques were used (with similar results).

Table 6. Results for Case 2 (non-linear value functions, NL).

\begin{tabular}{|c|c|c|c|c|c|c|c|}
\hline $\begin{array}{l}\text { Optimisation } \\
\text { Technique }\end{array}$ & $\begin{array}{l}\text { Variables, } \\
\text { Parameters } \\
\text { and Indices }\end{array}$ & \multicolumn{6}{|c|}{ Sets of Weights $\left(\beta_{i}\right)$} \\
\hline \multirow{10}{*}{$\begin{array}{c}\text { Exhaustive } \\
\text { search }\end{array}$} & $D_{S}(\mathrm{~m})$ & 0.6727 & 0.6621 & 0.6621 & 0.6621 & 0.6727 & 0.6727 \\
\hline & $d_{0}(\mathrm{~m})$ & 0.0080 & 0.0080 & 0.0080 & 0.0080 & 0.0080 & 0.0080 \\
\hline & $M(\mathrm{~kg})$ & 1231.8 & 1221.2 & 1221.2 & 1219.3 & 1237.5 & 1237.5 \\
\hline & $C_{i n v}(€)$ & 65,412 & 64,996 & 64,996 & 64,921 & 65,636 & 65,636 \\
\hline & $C_{o d c}(€)$ & 12,056 & 12,845 & 12,845 & 12,992 & 11,661 & 11,661 \\
\hline & $C 1(€)$ & 77,468 & 77,841 & 77,841 & 77,913 & 77,297 & 77,297 \\
\hline & $E I$ & 0.2754 & 0.2749 & 0.2749 & 0.2748 & 0.2757 & 0.2757 \\
\hline & SOI & 0.1335 & 0.1335 & 0.1335 & 0.1335 & 0.1336 & 0.1336 \\
\hline & ENI & 0.3788 & 0.3775 & 0.3778 & 0.3746 & 0.3807 & 0.3819 \\
\hline & $S I$ & 0.7877 & 0.7859 & 0.7862 & 0.7829 & 0.7900 & 0.7912 \\
\hline
\end{tabular}


Similar comments that were made for Case 1 in terms of weighting and in terms of optimisation techniques are, again, applicable. However, it is important to compare the differences in the results between Cases 1 and 2. The maximum difference in the SI between the two cases reaches a value of 0.0135 , which can be considered as insignificant. At the time of defining the non-linear value functions, the general criterion was to reward those values close to the best possible ones, and to considerably penalise those values far from the best possible ones; although with different levels of exigency. This explains why, in the second case, a highest SI was obtained. At the same time, this explains why, in the second case, the minimum SI reaches a lowest value (0.21). In terms of $D_{s}, d_{0}$ and $B$, the second case values vary between 0.66 and $0.67 ; 0.008$ and $0.0081 \mathrm{~m}$; and 0.48 and $0.5 \mathrm{~m}$. From three variables, two of them $\left(d_{0}\right.$ and $\left.B\right)$ vary between the same values in both Case 1 and 2. $D_{S}$ presents bigger deviations (the highest difference takes a value under $8 \mathrm{~cm}$ ), being the value functions' geometries the main reason for that. On the other hand, at the time of producing the real STHE, the two cases are likely to generate the same solution, if normalised values are used.

On the basis of the above, it can be concluded that the proposed model is robust, since big differences were not found at the time of: (i) considering different sets of weights for the environmental impacts, (ii) using different optimisation techniques, and (iii) establishing alternative levels of exigency and geometries for the value functions.

\subsection{General Results Discussion}

Once the different cases were compared, it is possible to analyse the nexus between economics, environment and sustainability. To that end, it is necessary to separately establish the Economic Index $(E I)$ and the Environmental Index (ENI) as objective functions. To do so, only the results obtained with the exhaustive search technique, for the linear case with the weights included in Table 1 will be considered. Similar comments will be applicable if other cases are studied. The results are shown in Table 7.

Table 7. Additional results for Case 1 (linear value functions, L). Environmental weights based on Ref. [31].

\begin{tabular}{|c|c|c|c|c|}
\hline \multirow{2}{*}{$\begin{array}{l}\text { Optimisation } \\
\text { Technique }\end{array}$} & \multirow{2}{*}{$\begin{array}{l}\text { Variables, Parameters and } \\
\text { Indices }\end{array}$} & \multicolumn{3}{|c|}{ Objective Function } \\
\hline & & $S I$ & $E I$ & ENI \\
\hline \multirow{12}{*}{ Exhaustive search } & $D_{S}(\mathrm{~m})$ & 0.7152 & 0.7364 & 0.6409 \\
\hline & $d_{0}(\mathrm{~m})$ & 0.0080 & 0.0080 & 0.0080 \\
\hline & $B(\mathrm{~m})$ & 0.5000 & 0.5000 & 0.4955 \\
\hline & $A\left(\mathrm{~m}^{2}\right)$ & 222.49 & 226.48 & 209.06 \\
\hline & $M(\mathrm{~kg})$ & 1281.5 & 1304.5 & 1204.2 \\
\hline & $C_{i n v}(€)$ & 67,356 & 68,252 & 64,329 \\
\hline & $C_{o d c}(€)$ & 9174 & 8209 & 14,349 \\
\hline & $C 1(€)$ & 76,530 & 76,461 & 78,678 \\
\hline & $E I$ & 0.2608 & 0.2610 & 0.2545 \\
\hline & SOI & 0.1338 & 0.1339 & 0.1334 \\
\hline & ENI & 0.3840 & 0.3834 & 0.3860 \\
\hline & $S I$ & 0.7786 & 0.7783 & 0.7739 \\
\hline
\end{tabular}

Obviously, when the $E I$ is established as the objective function, the highest $E I$ is obtained. This also happens with the ENI. On the other hand, looking at the design parameters, it can be concluded that $d_{0}$ and $B$ almost take the same values for the different objective functions. The difference in the value that $D_{s}$ adopts reaches a maximum of $9.55 \mathrm{~cm}$. Despite this, the different indices took similar values. Therefore, it can be concluded that different designs can generate similar results from economic, social, environmental and sustainability perspectives.

In this particular case, maximising the $E N I$ is equivalent to minimise the mass $(M)$ used. This is the reason why the smallest mass is obtained when the ENI is considered as the objective function. This explains that $D_{s}$ has adopted the smallest value when ENI is maximised. Consequently, when 
ENI is the objective function, the number of tubes $\left(N_{t}\right)$ also takes the minimum value (3768). Smaller values of $D_{s}$ and $N_{t}$ lead to higher fluid velocities [17]. This, in turn, generates higher pressure drops both for the tube and shell sides [17]. Consequently, the operating costs $\left(C_{o d c}\right)$ are higher than the ones obtained when SI and $E I$ are the objective functions. In fact, the increase in the operating costs is large enough to generate the largest total cost (C1). This happens despite the fact that the capital investment $\left(C_{i n v}\right)$ is the lowest one. When the ENI is maximised, $A$ takes a value of $209 \mathrm{~m}^{2}$. However, in the other two cases, the area is higher $\left(222.5\right.$ and $\left.226.5 \mathrm{~m}^{2}\right)$. This can be shocking, since the capital investment cost increases with the area, as is deducted from Equation (9). Therefore, maximising the EI (equivalent to reduce the costs) should be associated with an area minimisation. Nevertheless, the design with the minimum area will not necessarily have the minimum total cost (C1), even if it has the minimum investment cost, since a minimum area can lead to higher velocities and pressure drops. This is what happens in this case. When the $E I$ is the objective function, the total cost $C 1$ is the lowest one (76,462€ in comparison with $76,530 €$ and $78,678 €$ for the SI and ENI cases, respectively), although the investment cost is not the minor one. Therefore, maximising the ENI and maximising the $E I$ are not completely equivalent, although the two are related. On the other hand, maximising the SI is a trade-off solution between maximising the $E I$ and the ENI. In other words, when the $S I$ is the objective function, the partial indices are slightly reduced in comparison with the possible best results, but for obtaining a better global design.

\subsection{Comparisons with the Existing Literature}

The results obtained here can also be compared with the unique study addressing the sustainability optimisation of an STHE [17]. Taking into account that a considerable number of cases are addressed in this study, only the results obtained in Case 1, when an exhaustive search approach is adopted and when the weights of Table 1 are used will be compared with the ones of [17], in particular for the baseline case. Regarding the SI, the maximum value presented in [17] was close to 0.79 , which is similar to the one presented in this study. The optimisation variables are also similar. In fact, $d_{0}$ and $B$ take exactly the same values. The shell internal diameters are different, but with a variation of only $2 \mathrm{~cm}$. In fact, the shell internal diameter of [17] is smaller than the one obtained in this paper (Table 5). Consequently, the number of tubes is also smaller [17]. This in turn leads to higher fluid velocities, higher pressure drops and also higher operating costs $(10,312 €$ in contrast with the value of $9174 €$ included in Table 5). Despite this, there is only a difference of $266 €$ in the total cost (C1) between this study and Ref. [17]. This is due to the fact that $A$ takes a lower value in [17], generating a smaller capital investment $\operatorname{cost}\left(C_{i n v}\right)$. In this particular case, a smaller value of $A$ is also linked to a smaller consumption of steel $(M)$. Therefore, the optimal design of [17] presents a slightly better performance from and environmental point of view. Nevertheless, the reader should take into account that the optimal design found here and the one provided in [17] are so similar that they will be exactly the same in a practical application, using commercial diameters. These parallels appear, although a greater number of environmental indicators was considered in this study. Nevertheless, this does not infer that the amount of environmental indicators is not important. The ideal situation would be to study all the existing environmental effects, since each impact needs different measures to be corrected.

Other authors analysed the same case study, with the total cost (C1) as the objective function. Since the objective function is not the same as the one included in this study, considerable differences may appear in all the design parameters. As a way of comparing the results between this and other papers, the authors introduced, in the model presented here, the values of the design variables $\left(D_{s}, d_{0}\right.$ and $\left.B\right)$ obtained in the existing literature (Table 8). It is important to clarify that, in Table 8, the values adopted by some of the parameters do not necessarily coincide with the ones presented in the corresponding references, since there can be small variations in the mathematical model. Once again, the exhaustive search approach for the linear case with the weights based on [31] were considered. 
Table 8. Results of the existing literature obtained with the model developed in this study (exhaustive search approach, linear case (L), weights based on [31]).

\begin{tabular}{|c|c|c|c|c|c|c|c|c|c|c|c|c|c|c|}
\hline \multirow{2}{*}{$\begin{array}{c}\text { Variables, } \\
\text { Parameters and } \\
\text { Indices }\end{array}$} & \multicolumn{14}{|c|}{ Existing Literature } \\
\hline & $\begin{array}{l}\text { Ref. } \\
\text { [11] }\end{array}$ & $\begin{array}{l}\text { Ref. } \\
\text { [12] }\end{array}$ & $\begin{array}{l}\text { Ref. } \\
\text { [13] }^{\mathbf{a}}\end{array}$ & $\begin{array}{l}\text { Ref. } \\
\text { [13] }^{\text {a }}\end{array}$ & $\begin{array}{l}\text { Ref. } \\
\text { [14] }\end{array}$ & $\begin{array}{l}\text { Ref. } \\
\text { [35] }\end{array}$ & $\begin{array}{l}\text { Ref. } \\
\text { [37] }\end{array}$ & $\begin{array}{l}\text { Ref. } \\
\text { [38] }\end{array}$ & $\begin{array}{l}\text { Ref. } \\
\text { [39] }^{\mathbf{b}}\end{array}$ & $\begin{array}{l}\text { Ref. } \\
\text { [39] }^{\mathbf{b}}\end{array}$ & $\begin{array}{l}\text { Ref. } \\
\text { [40] }^{\mathrm{c}}\end{array}$ & $\begin{array}{l}\text { Ref. } \\
\text { [40] }^{\text {c }}\end{array}$ & $\begin{array}{l}\text { Ref. } \\
\text { [41] }\end{array}$ & $\begin{array}{l}\text { Ref. } \\
\text { [42] }\end{array}$ \\
\hline$D_{S}(\mathrm{~m})$ & 0.8100 & 0.8790 & 0.8290 & 0.8290 & 0.7800 & 0.8300 & 0.8010 & 0.8260 & 0.7620 & 0.7635 & 0.7270 & 0.7290 & 0.7683 & 0.6822 \\
\hline$d_{0}(\mathrm{~m})$ & 0.0150 & 0.0150 & 0.0150 & 0.0150 & 0.0100 & 0.0160 & 0.0100 & 0.0151 & 0.0101 & 0.0100 & 0.0114 & 0.0114 & 0.0100 & 0.0101 \\
\hline$B(\mathrm{~m})$ & 0.4240 & 0.5000 & 0.3850 & 0.3830 & 0.5000 & 0.5000 & 0.5000 & 0.4140 & 0.4988 & 0.4955 & 0.4500 & 0.4500 & 0.5000 & 0.5000 \\
\hline$A\left(\mathrm{~m}^{2}\right)$ & 255.56 & 282.26 & 254.11 & 253.87 & 242.92 & 271.61 & 247.08 & 257.45 & 239.74 & 239.33 & 230.04 & 230.35 & 240.64 & 221.73 \\
\hline$M(\mathrm{~kg})$ & 2760.0 & 3048.4 & 2744.4 & 2741.8 & 1749.1 & 3129.0 & 1779.0 & 2799.0 & 1743.4 & 1723.2 & 1888.2 & 1890.7 & 1732.6 & 1612.4 \\
\hline$C_{i n v}(€)$ & 74,743 & 80,643 & 74,421 & 74,367 & 71,931 & 78,297 & 72,858 & 75,163 & 71,220 & 71,130 & 69,052 & 69,121 & 71,423 & 67,186 \\
\hline$C_{o d c}(€)$ & 9052 & 5282 & 9999 & 10,100 & 7098 & 6536 & 6444 & 8858 & 7790 & 7782 & 11,014 & 10,901 & 7507 & 11,772 \\
\hline $\mathrm{C} 1(€)$ & 83,795 & 85,925 & 84,420 & 84,467 & 79,029 & 84,833 & 79,302 & 84,021 & 79,010 & 78,912 & 80,066 & 80,022 & 78,930 & 78,958 \\
\hline$E I$ & 0.2394 & 0.2332 & 0.2376 & 0.2375 & 0.2535 & 0.2364 & 0.2527 & 0.2388 & 0.2535 & 0.2538 & 0.2504 & 0.2505 & 0.2538 & 0.2537 \\
\hline SOI & 0.1408 & 0.1421 & 0.1407 & 0.1407 & 0.1360 & 0.1425 & 0.1361 & 0.1409 & 0.1360 & 0.1359 & 0.1366 & 0.1367 & 0.1359 & 0.1353 \\
\hline ENI & 0.3460 & 0.3386 & 0.3464 & 0.3464 & 0.3720 & 0.3365 & 0.3712 & 0.3450 & 0.3721 & 0.3727 & 0.3864 & 0.3683 & 0.3724 & 0.3755 \\
\hline$S I$ & 0.7262 & 0.7139 & 0.7247 & 0.7246 & 0.7615 & 0.7154 & 0.7600 & 0.7247 & 0.7616 & 0.7624 & 0.7554 & 0.7555 & 0.7621 & 0.7645 \\
\hline
\end{tabular}

${ }^{a}$ The authors employed two different optimisation techniques. The resulting solutions do not fulfil the restrictions established in this study. ${ }^{\mathrm{b}}$ The authors employed two different optimisation techniques. ${ }^{\mathrm{c}}$ The authors employed two different optimisation techniques. 
Before comparing and discussing the results of this study and the existing literature, the reader must bear in mind that the differences among them are mainly based on: (i) variations in the mathematical model since there are alternative equations to estimate some of the STHE parameters (for example: the convective coefficients), (ii) different optimisation techniques, (iii) different values for the numerical constants of Equation (9). The latter is due to the fact that most of the authors did not update Equation (9) by taking into account the time value of money, as we did.

Some of the results are in proximity to the ones presented in this study. Even in the cases in which the differences are bigger, they are not very significant if one takes into account the ranges of possible values defined in Section 3.1. The SIs included in Table 8 are always below the one presented in Table 7 (SI optimisation). This is a logical outcome since, in the existing literature, the objective was to minimise the total costs (C1), instead of maximising the integral sustainability.

On the other hand, the EIs obtained in this paper, even when they are not the objective function, are higher (Table 7) than the ones presented in Table 8. In other words, the results shown in this study are also better from an economic point of view. This could be a consequence of the minor differences that can exist in the mathematical model, and also in the Hall correlation among the studies, as previously alluded to. As a result, if the design parameters presented in Table 7 are introduced in other authors' models, the EIs are likely to be worse than the ones obtained with the authors' variables. Nevertheless, the same will not happen in terms of integral sustainability.

The best results of the existing literature in terms of costs ([39], $D_{s}=0.7635, d_{0}=0.01$ and $B=0.4955$ ) and in terms of sustainability (Ref. [42], $D_{s}=0.6822, d_{0}=0.0101$ and $B=0.5$ ) will be discussed in greater detail. In particular, the results of [39] will be compared with the ones of Table 7 when EI is the fitness function $\left(D_{s}=0.7364, d_{0}=0.008\right.$ and $\left.B=0.5\right)$, while the results of [42] will be compared with the ones of Table 5, when an exhaustive search is used and when the weights of Table 1 are employed ( $D_{s}=0.7152, d_{0}=0.008$ and $B=0.5$, also shown in Table 7 when $S I$ is the fitness function).

When the $E I$ is the objective function (Table 7), the optimisation variables $\left(D_{s}, d_{0}\right.$ and $\left.B\right)$ take similar values to the ones adopted in [39]. In fact, the higher variation occurs for the shell internal diameter and it takes a value of $2.7 \mathrm{~cm}$. As the value adopted by $D_{s}$ in [39] is higher, one might think that the number of tubes will also be higher. This may be the case if $d_{0}$ takes the same value in both studies. Nevertheless, in this case, the tube outside diameter $\left(d_{0}\right)$ is also bigger in [39], resulting in a lower number of tubes. As the velocities resulted to be similar, the difference in the total pressure drop is reduced [17]. This results in a $427 €$ difference between the total operating costs of the two studies, which is not relevant. This difference is bigger for the capital investment $\left(C_{i n v}\right)$, since the design of [39] presents an area equal to 1.06 times the valued adopted in this study. Despite all these variations, the two solutions can be considered as high-performing in terms of cost.

In spite of the fact that existing studies (Table 8) did not aim the sustainability optimisation, promising results were obtained in terms of SI. The design of [42] presents a lower $D_{s}$ than the one listed in Tables 5 and 7. However, the tube outside diameter is bigger. Thus, the number of tubes were considerably lower, generating higher fluid velocities, pressure drops and operating costs. Nevertheless, this is one of the cases in which a larger value of $A$ is not associated with a higher value of $M$. The design of [42] presents a surface area of $221.73 \mathrm{~m}^{2}, 0.76 \mathrm{~m}^{2}$ less than the one obtained in this study. Consequently, [42] has obtained better results in terms of capital investment. Despite this, its total cost is still over the one included in Tables 5 and 7. On the other hand, the amount of stainless steel employed in [42] is greater. This translates into more significant environmental impacts. As the environmental dimension is the most important one, the $S I$ is not as big as the one obtained in this study.

\section{Conclusions and Further Research}

Sustainability optimisation can be a key tool for achieving a project's sustainability objective. In this manuscript, the optimisation of a STHE is addressed by taking into account a great number of indicators, covering the economic, social and environmental dimensions of sustainability. A total number of 
15 environmental impact categories were included, covering those impacts that are not frequently considered in the existing literature. Different sets of weights were defined for the environmental impacts. Moreover, two different cases were analysed (linear and non-linear) at the time of assessing the indicators. A case study previously considered in the literature was solved, by using different optimisation techniques. The most important findings of this study are:

- There are great differences in the contribution to the integral sustainability among all the valid STHE designs. Therefore, it is always desirable to apply such a type of technique to find the most sustainable solution. In other words, the optimal or sub-optimal solutions presented SIs close to 0.78 , while there are valid designs with SIs near to 0.30 and 0.20 for the linear and non-linear cases, respectively;

- The sustainability model appeared to be robust, since big differences were not found in the design variables when: (i) various sets of weights were considered, (ii) different optimisation techniques were used, and (iii) linearities and non-linearities were defined. The reader should bear in mind that these conclusions are not general, since, in other optimisation problems, different results can arise;

- Nature-inspired optimisation techniques are not strictly necessary in this case study. However, the opposite may occur if the number of optimisation variables grows considerably or if discrete indicators are used;

- Minimising the environmental impacts is, to a certain extent, linked to a capital investment minimization;

- In this particular case, optimising the costs, optimising the environmental impacts and optimising the SI are almost equivalent. In fact, the real solution using normalised values is likely to be the same for both cases;

- There are some connections among the optimisation of the SI, ENI and EI. Consequently, when each one of this indices is optimised, promising results are expected for the remaining ones;

- Strong results are not possible from a social point of view, since there is a conflict among the indicators;

- At the time of designing a STHE, the optimisation of the SI is a trade-off solution between maximising the $E I$ and maximising the $E N I$;

- Sustainability optimisation processes such as the one presented here can be useful, within the framework of project management, to establish the sustainability strategy of the project, and to increase the chances of meeting the sustainability objective.

Regarding future applications, the authors aim to apply the integrated optimisation methodology to more complex energy systems. The option of trying more optimisation techniques must also be studied.

It is important to note that this model can be modified by other researchers to optimise the sustainability of different heat exchangers. Furthermore, the proposed methodology can be applied to optimise other energy systems. In such cases, the mathematical model must be replaced by the corresponding one. The indicators of the MIVES model could be the same, although the value functions, as well as the way in which each indicator is estimated, should be updated according to the new design model. Applying this technique for designing energy systems that are mass produced will result in a major contribution to sustainable development.

Author Contributions: Conceptualization, J.J.C.B, M.L.C., M.P.d.1.C.L., A.d.C.G. and I.S.; methodology, J.J.C.B., M.L.C., M.P.d.l.C.L., A.d.C.G. and I.S.; software, J.J.C.B.; validation, J.J.C.B., M.L.C., M.P.d.l.C.L., A.d.C.G. and I.S.; formal analysis, J.J.C.B., M.L.C., M.P.d.l.C.L. and A.d.C.G.; investigation, J.J.C.B.; resources, A.d.C.G.; data curation, J.J.C.B.; writing-original draft preparation, J.J.C.B.; writing-review and editing, J.J.C.B, M.L.C., M.P.d.l.C.L., A.d.C.G. and I.S.; visualization, J.J.C.B. and A.d.C.G.; supervision, A.d.C.G. and I.S. All authors have read and agreed to the published version of the manuscript.

Funding: This research received no external funding. 
Conflicts of Interest: The authors declare no conflict of interest. The funders had no role in the design of the study; in the collection, analyses, or interpretation of data; in the writing of the manuscript, or in the decision to publish the results.

\section{References}

1. Soares, I.; Ferreira, P.; Lund, H. Energy transition: The economics \& engineering nexus. Energy 2019, 166, 961-962.

2. Cartelle Barros, J.J.; Lara Coira, M.; de la Cruz López, M.P.; del Caño Gochi, A.; Soares, I. Sustainability optimisation of shell and tube heat exchanger using different optimisation techniques. In Proceedings of the 4th International Conference on Energy E Environment: Bringing together Engineering and Economics, Guimarães, Portugal, 16-17 May 2019; Ferreira, P., Soares, I., Eds.; University of Minho: Guimaraes, Portugal, 2019; pp. 307-315.

3. Moore, J.; Grimes, R.; Walsh, E.; O'Donovan, A. Modelling the thermodynamic performance of a concentrated solar power plant with a novel modular air-cooled condenser. Energy 2014, 69, 378-391. [CrossRef]

4. Shirazi, A.; Najafi, B.; Aminyavari, M.; Rinaldi, F.; Taylor, R.A. Thermal-economic-environmental analysis and multi-objective optimization of an ice thermal energy storage system for gas turbine cycle inlet air cooling. Energy 2014, 69, 212-226. [CrossRef]

5. Da Silva, P.P.; Cerqueira, P.A.; Ogbe, W. Determinants of renewable energy growth in Sub-Saharan Africa: Evidence from panel ARDL. Energy 2018, 156, 45-54. [CrossRef]

6. Singh, V.K.; Henriques, C.O.; Martins, A.G. Fostering investment on energy efficient appliances in India-A multi-perspective economic input-output lifecycle assessment. Energy 2018, 149, 1022-1035. [CrossRef]

7. Brundtland, G.H.; Khalid, M.; Agnelli, S.; Al-Athel, S.; Chidzero, B.; Fadika, L.; Hauff, V.; Lang, I.; Shijun, M. Our Common Future; Oxford University Press: Oxford, UK, 1987.

8. United Nations. Rio Declaration on Environment and Development; United Nations: Rio of Janeiro, Brazil, 1992.

9. Manara, P.; Zabaniotou, A. Indicator-based economic, environmental, and social sustainability assessment of a small gasification bioenergy system fuelled with food processing residues from the Mediterranean agro-industrial sector. Sustain. Energy Technol. Assess. 2014, 8, 159-171. [CrossRef]

10. Yılmaz Balaman, Ş.; Scott, J.; Matopoulos, A.; Wright, D.G. Incentivising bioenergy production: Economic and environmental insights from a regional optimization methodology. Renew. Energy 2019, 130, 867-880. [CrossRef]

11. Patel, V.K.; Rao, R.V. Design optimization of shell-and-tube heat exchanger using particle swarm optimization technique. Appl. Therm. Eng. 2010, 30, 1417-1425. [CrossRef]

12. Hadidi, A.; Hadidi, M.; Nazari, A. A new design approach for shell-and-tube heat exchangers using imperialist competitive algorithm (ICA) from economic point of view. Energy Convers. Manag. 2013, 67, 66-74. [CrossRef]

13. Mariani, V.C.; Duck, A.R.K.; Guerra, F.A.; Coelho, L.D.S.; Rao, R.V. A chaotic quantum-behaved particle swarm approach applied to optimization of heat exchangers. Appl. Therm. Eng. 2012, 42, 119-128. [CrossRef]

14. Dhavle, S.V.; Kulkarni, A.J.; Shastri, A.; Kale, I.R. Design and economic optimization of shell-and-tube heat exchanger using cohort intelligence algorithm. Neural Comput. Appl. 2018, 30, 111-125. [CrossRef]

15. Sanaye, S.; Hajabdollahi, H. Multi-objective optimization of shell and tube heat exchangers. Appl. Therm. Eng. 2010, 30, 1937-1945. [CrossRef]

16. Mirzaei, M.; Hajabdollahi, H.; Fadakar, H. Multi-objective optimization of shell-and-tube heat exchanger by constructal theory. Appl. Therm. Eng. 2017, 125, 9-19. [CrossRef]

17. Cartelle Barros, J.J.; Lara Coira, M.; de la Cruz López, M.P.; del Caño Gochi, A. Sustainability optimisation of shell and tube heat exchanger, using a new integrated methodology. J. Clean. Prod. 2018, 200, 552-567. [CrossRef]

18. European Commission. International Reference Life Cycle Data System Handbook-Recommendations for Life Cycle Impact Assessment in the European Context; European Commission, Joint Research Centre, Institute for Environment and Sustainability: Luxemburg, 2011.

19. Del Caño, A.; de La Cruz, M.P.; Cartelle, J.J.; Lara, M. Conceptual Framework for an Integrated Method to Optimize Sustainability of Engineering Systems. J. Energy Power Eng. 2015, 9, 608-615. 
20. Casanovas-rubio, M.; Pujadas, P.; Pardo-bosch, F.; Blanco, A.; Aguado, A. Sustainability assessment of trenches including the new eco-trench: A multi-criteria decision-making tool. J. Clean. Prod. 2019, 238, 117957. [CrossRef]

21. Floudas, C.A.; Pardalos, P.M. Encyclopedia of Optimization, 2nd ed.; Floudas, C.A., Pardalos, P.M., Eds.; Springer: Berlin/Heidelberg, Germany, 2009; ISBN 978-0-387-74758-3.

22. Huang, Y.H.; Wu, J.H.; Hsu, Y.J. Two-stage stochastic programming model for the regional-scale electricity planning under demand uncertainty. Energy 2016, 116, 1145-1157. [CrossRef]

23. Rigo-Mariani, R.; Chea Wae, S.O.; Mazzoni, S.; Romagnoli, A. Comparison of optimization frameworks for the design of a multi-energy microgrid. Appl. Energy 2020, 257, 113982. [CrossRef]

24. Pizarro-Alonso, A.; Ravn, H.; Münster, M. Uncertainties towards a fossil-free system with high integration of wind energy in long-term planning. Appl. Energy 2019, 253, 113528. [CrossRef]

25. Bozorg-Haddad, O. Advanced Optimization by Nature-Inspired Algorithms; Kacprzyk, J., Ed.; Springer: Singapore, 2018; ISBN 9789811052200.

26. Rezaee Jordehi, A.; Jasni, J. Parameter selection in particle swarm optimisation: A survey. J. Exp. Theor. Artif. Intell. 2013, 25, 527-542. [CrossRef]

27. Kennedy, J.; Eberhart, R. Particle swarm optimization. In Proceedings of the IEEE International Conference on Neural Networks-Conference Proceedings, Perth, Australia, 27 November-1 December 1995; pp. 1942-1948.

28. Poli, R.; Kennedy, J.; Blackwell, T. Particle swarm optimization: An overview. Swarm Intell. 2007, 1, 33-57. [CrossRef]

29. Askarzadeh, A. A novel metaheuristic method for solving constrained engineering optimization problems: Crow search algorithm. Comput. Struct. 2016, 169, 1-12. [CrossRef]

30. Deb, K.; Pratap, A.; Agarwal, S.; Meyarivan, T. A fast and elitist multiobjective genetic algorithm: NSGA-II. IEEE Trans. Evol. Comput. 2002, 6, 182-197. [CrossRef]

31. Kupfer, T.; Baitz, M.; Colodel, C.M.; Kokborg, M.; Schöll, S.; Rudolf, M.; Thellier, L.; Gonzalez, M.; Schuller, O.; Hengstler, J.; et al. GaBi Database and Modelling Principles 2017; Thinkstep: Leinfelden-Echterdingen, Germany, 2017.

32. Cartelle Barros, J.J.; Lara Coira, M.; de la Cruz López, M.P.; del Caño Gochi, A. Assessing the global sustainability of different electricity generation systems. Energy 2015, 89, 473-489. [CrossRef]

33. Caputo, A.C.; Pelagagge, P.M.; Salini, P. Manufacturing cost model for heat exchangers optimization. Appl. Therm. Eng. 2016, 94, 513-533. [CrossRef]

34. Taal, M.; Bulatov, I.; Klemeš, J.; Stehlík, P. Cost estimation and energy price forecasts for economic evaluation of retrofit projects. Appl. Therm. Eng. 2003, 23, 1819-1835. [CrossRef]

35. Caputo, A.C.; Pelagagge, P.M.; Salini, P. Heat exchanger design based on economic optimisation. Appl. Therm. Eng. 2008, 28, 1151-1159. [CrossRef]

36. Azad, A.V.; Amidpour, M. Economic optimization of shell and tube heat exchanger based on constructal theory. Energy 2011, 36, 1087-1096. [CrossRef]

37. Hadidi, A.; Nazari, A. Design and economic optimization of shell-and-tube heat exchangers using biogeography-based (BBO) algorithm. Appl. Therm. Eng. 2013, 51, 1263-1272. [CrossRef]

38. Asadi, M.; Song, Y.; Sunden, B.; Xie, G. Economic optimization design of shell-and-tube heat exchangers by a cuckoo-search-algorithm. Appl. Therm. Eng. 2014, 73, 1032-1040. [CrossRef]

39. Turgut, O.E.; Turgut, M.S.; Coban, M.T. Design and economic investigation of shell and tube heat exchangers using Improved Intelligent Tuned Harmony Search algorithm. Ain Shams Eng. J. 2014, 5, 1215-1231. [CrossRef]

40. de Vasconcelos Segundo, E.H.; Amoroso, A.L.; Mariani, V.C.; dos Santos Coelho, L. Economic optimization design for shell-and-tube heat exchangers by a Tsallis differential evolution. Appl. Therm. Eng. 2017, 111, 143-151. [CrossRef]

41. Rao, R.V.; Saroj, A. Constrained economic optimization of shell-and-tube heat exchangers using elitist-Jaya algorithm. Energy 2017, 128, 785-800. [CrossRef]

42. De Vasconcelos Segundo, E.H.; Mariani, V.C.; dos Santos Coelho, L. Design of heat exchangers using Falcon Optimization Algorithm. Appl. Therm. Eng. 2019, 156, 119-144. [CrossRef]

43. Thinkstep Professional Database. Available online: http://www.gabi-software.com/support/gabi/gabidatabase-2018-lci-documentation/professional-database-2018/-documentation/professional-database2014/ (accessed on 31 January 2019). 
44. Vidal-Legaz, B.; Sala, S.; Antón, A.; Maia De Souza, D.; Nocita, M.; Putman, B.; Teixeira, R.F.M. Land-Use Related Environmental Indicators for Life Cycle Assessment; Joint Research Centre: Luxembourg, 2016.

45. Castellani, V.; Benini, L.; Sala, S.; Pant, R. A distance-to-target weighting method for Europe 2020. Int. J. Life Cycle Assess. 2016, 21, 1159-1169. [CrossRef]

46. Huppes, G.; van Oers, L. Background Review of Existing Weighting Approaches in Life Cycle Impact Assessment (LCIA); European Commission, Joint Research Centre, Institute for Environment and Sustainability: Luxemburg, 2011.

47. Huppes, G.; Van Oers, L.; Pretato, U.; Pennington, D.W. Weighting environmental effects: Analytic survey with operational evaluation methods and a meta-method. Int. J. Life Cycle Assess. 2012, 17, $876-891$. [CrossRef]

(C) 2020 by the authors. Licensee MDPI, Basel, Switzerland. This article is an open access article distributed under the terms and conditions of the Creative Commons Attribution (CC BY) license (http://creativecommons.org/licenses/by/4.0/). 